Editorial

\title{
New and Advanced Materials and Technologies in Ultralow-Energy Buildings
}

\author{
G. Y. Yun $\mathbb{D}^{1},{ }^{1}$ A. Kwok, ${ }^{2}$ K. Steemers, ${ }^{3}$ and W. T. Grondzik ${ }^{4}$ \\ ${ }^{1}$ Kyung Hee University, Yongin, Republic of Korea \\ ${ }^{2}$ University of Oregon, Eugene, OR, USA \\ ${ }^{3}$ University of Cambridge, Cambridge, UK \\ ${ }^{4}$ Ball State University, Muncie, IN, USA \\ Correspondence should be addressed to G. Y. Yun; gyyun@khu.ac.kr
}

Received 2 July 2018; Accepted 2 July 2018; Published 1 August 2018

Copyright ( $\odot 2018$ G. Y. Yun et al. This is an open access article distributed under the Creative Commons Attribution License, which permits unrestricted use, distribution, and reproduction in any medium, provided the original work is properly cited.

The building sector is one of the largest contributors to energy consumption worldwide, representing $32 \%$ of the total energy consumption in the world and accounting for $60 \%$ of the world's electricity use. Thus, there have been significant efforts to reduce energy consumption in buildings. Ultralow-energy buildings are one successful approach to reducing carbon emissions in the building sector, attracting a growing interest worldwide. The principles of ultralow-energy building emphasize a passive building design and high-performance heating, ventilating, and airconditioning (HVAC) systems. Typical features include superinsulation, airtight envelopes, daylighting, highperformance windows, energy-efficient HVAC, and electrical lighting, which present significant technical challenges. For example, a low heat transfer coefficient of a passive building design, typically 0.10 to $0.15 \mathrm{~W} /\left(\mathrm{m}^{2} \mathrm{~K}\right)$, requires new and advanced materials for insulation in order to avoid unfeasibly thick construction. The realization of zero energy buildings has sparked innovations in HVAC systems by applying new materials and technologies. New materials and technologies are also indispensable for high-performance windows because they require both a low thermal transmittance and a high total solar transmittance.

Therefore, the development of new and advanced materials and technologies is a prerequisite to the widespread realization of ultralow-energy buildings. The resultant unique indoor environment of ultralow-energy buildings has significant implications for occupant comfort and energy performance simulation. The main aim of this special issue is to provide a platform for a wide range of professions to understand and discuss the major challenges and recent advancements in materials and technologies for ultralowenergy buildings.

One of the papers of the special issue by H. S. Lim and G. Kim develops a regression model to predict the heating loads of buildings. The unique aspect of this paper is that the regression model accounts for the effects of the time lag on heating energy demands. The study shows that the predictive performance increases by including the time lag effects. Another paper by K. Lee and S. Choo illustrates how building information modelling can be utilized in the early design stage to improve the energy efficiency of buildings and confirms that the architectural design elements are a key determinant of the building energy demand. A paper by Lee et al. investigates experimentally the energy performance of a variable refrigerant flow (VRF) system at full- and partload conditions. The results indicate that a VRF system considerably reduces the cooling and heating energy consumption, compared to a conventional roof top unit. A paper by Yoon et al. conducts a series of scale model experiments to examine the effects of phase change materials (PCMs) installed on the roof. The results indicate that the use of PCM decreases the surface temperature of the roof, and thus, the cooling load of the buildings is potentially reduced by the integration of PCM into the roof. A study by Lee et al. develops a light shelf integrated with a movable light reflector. A prototype of the light shelf was installed in the test bed and was operated to improve the daylight 
distribution and lighting energy performance. The authors found that the proposed light shelf can reduce lighting energy consumption by $20 \%$. A study by S. Lee and J. Seo examines the emission rate of di-2-ethylhexyl phthalate (DEHP), which is commonly used in building materials, using the thermal desorption test chamber method. The experiment found that the emission rate increases under high temperatures but is independent of relative humidity conditions. A paper by S.-T. No and J.-S. Seo carries out measurements of $U$-value of 532 window systems using the hot-box method and proposes regression models, which can be used to estimate the window system performance in the design stage. A research study by W. J. Chung and J.-H. Lim proposes a new design method for a thermally activated building system. The proposed method consists of an airside system handling the latent load with the thermally activated building system controlling the sensible load. The study reveals that the proposed design method can improve the efficiency of the thermally activated building system. A paper by Choi et al. explores an optimization method for insulation to improve energy performance, while minimizing the life cycle cost. The study illustrates that the decision-support method of this paper can be applied to derive effective energy conservation measures for buildings.

In summary, this journal presents modelling, design strategies, systems, materials, and components that are key aspects of ultralow-energy buildings.

G. Y. Yun

A. Kwok

K. Steemers

W. T. Grondzik 


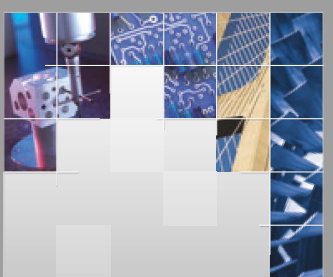

\section{Enfincering}
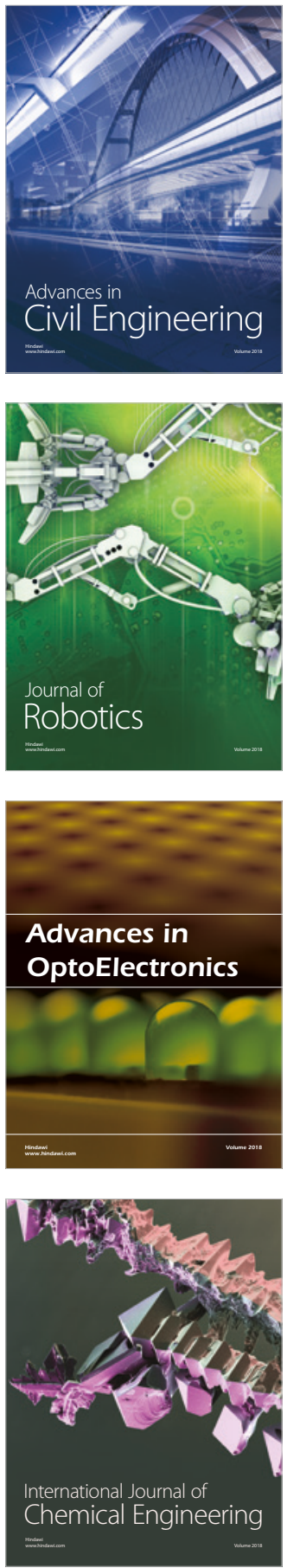

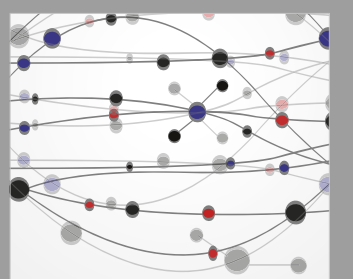

\section{Rotating \\ Machinery}

The Scientific World Journal

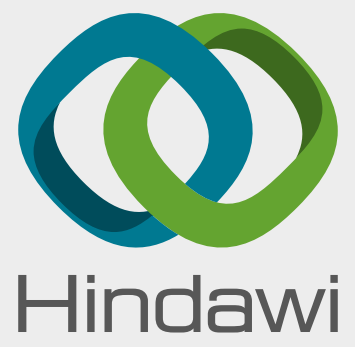

Submit your manuscripts at

www.hindawi.com
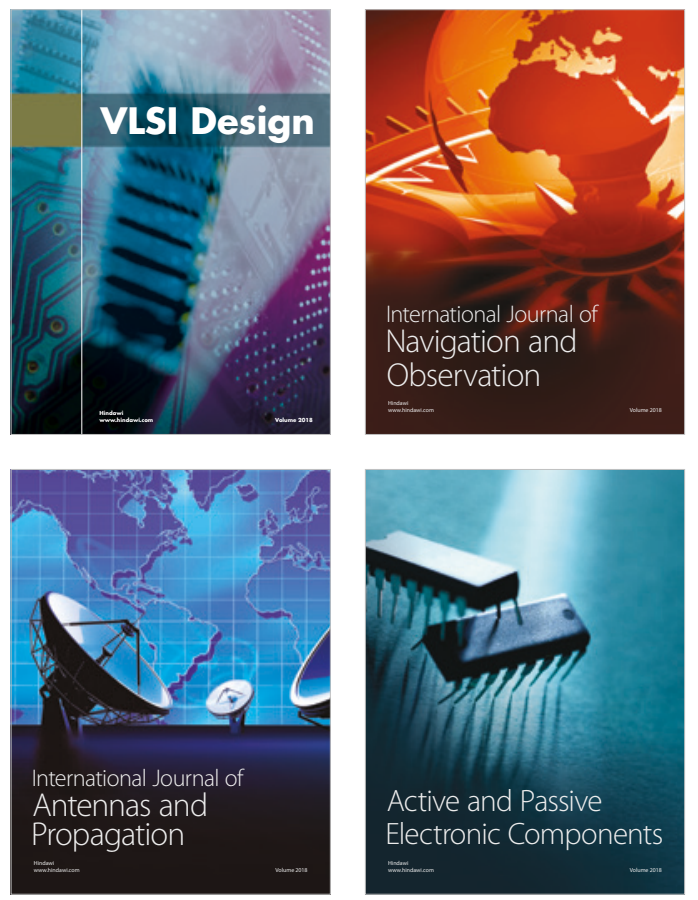
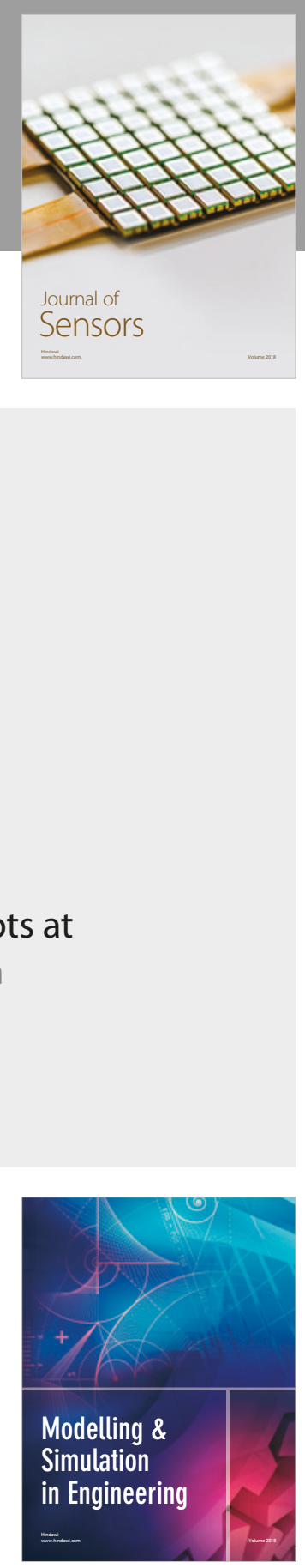

\section{Advances \\ Multimedia}
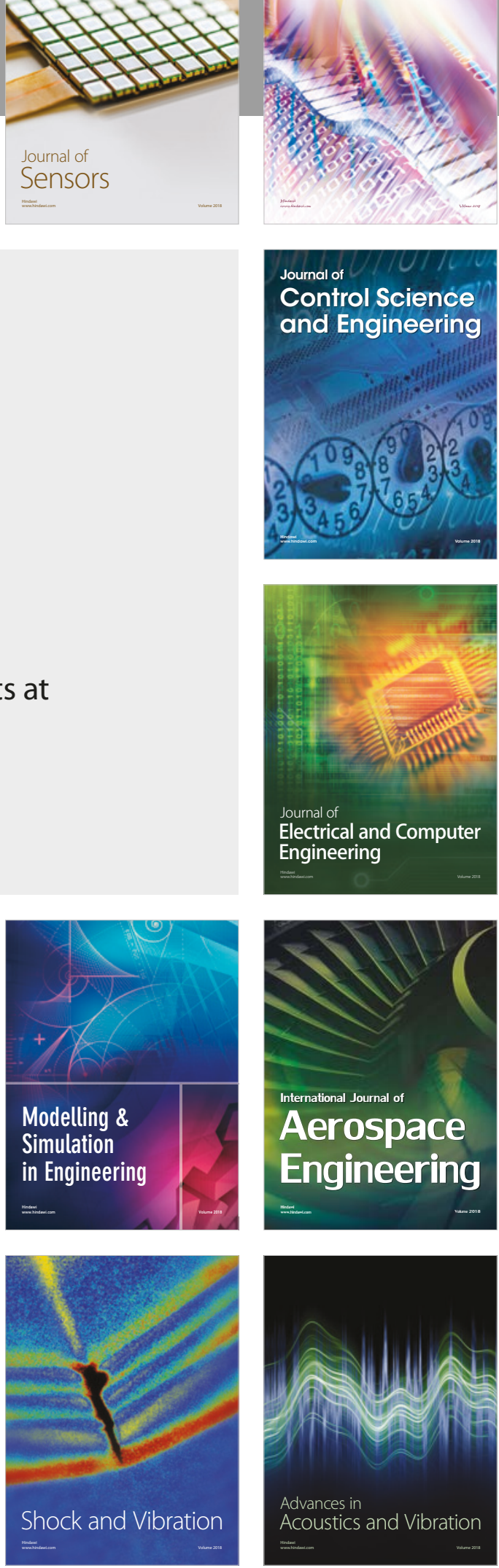